\title{
Mind the Gap: a Collaborative Competence e-Learning Model between University and Industry
}

\author{
Monika Hattinger \\ University West, Sweden \\ monika.hattinger@hv.se
}

\author{
Kristina Eriksson \\ University West, Sweden \\ kristina.eriksson@hy.se
}

\begin{abstract}
This article departure from the effects that interorganizational collaboration brings for the participating partners, specifically from design-related activities of e-learning courses and co-production. The research focus is on critical factors for interorganizational collaborative e-learning and coproduction between university and industry. We describe the process of a six-year longitudinal collaborative action research project including six cases and three phases, initialization, implementation and dissemination. The analysis is conducted from a multi-stakeholder perspective; managers, teachers, and practitioners. Overall aim is to reach for a sustainable collaborative competence e-learning model (CCeM) that will increase industrial employees' competences. Main contribution is that co-production of knowledge entails three levels of activities among actors; to have insight into the purposes and practices of others, the capacity to transform the problems of a practice and together build common knowledge and finally the capacity of mutually co-produce knowledge acted upon in practice towards transformations in the workplace.
\end{abstract}

\section{Introduction}

This research departure from the effects that longitudinal and inter-organizational collaboration create for the participating partners [1]. In such collaboration the interest is on mutual design activities that evolve when an organization causes a change in the capacity of another, through knowledge sharing, knowledge building and learning [2, 3]. Particularly, this research draws on critical factors of interorganizational collaboration between university and industry, meaning effects from activities that interrelate co-production and e-learning design with aim to strengthen industrial competence.

Inter-organizational collaboration has received substantial research interest within organization, management and communication studies [4]. There is also a growing body of studies showing success factors within the health education field [5] as well as studies of educational-related partnership between university and the engineering business field [6]. Besides benefits of inter-organizational collaboration raised in these recent studies, they also raise complications of interorganizational collaboration, e.g., cultural differences, different time dependence, obstacles of mutual problem domain sharing etc. $[4,5]$. However, these research fields do not in particular consider universityindustry collaborative aspects that include and combine design-related knowledge and work [7]. Design-related activities may cause dilemmas and conflicts in the process of co-production of knowledge and e-learning when developing an e-learning course program [8]. Given, this, we argue there is a further need of research on the effects of inter-organizational collaborative studies addressing interrelations of co-production and e-learning design.

We argue for novel research that take a multiperspective view on e-learning design and collaborations with an action research (AR) approach [9], especially when combining AR with action design research (ADR) [10]. Combining AR with design research creates a way of thinking that interrelate technology, processes and organization for understanding design as its own culture of inquiry and action [11]. Furthermore, AR with a design approach gives directions on a collaborative practice research as a way to organize and conduct research based on close relationships between teachers and practitioners [12]. Given this, we highlight the need to use AR approaches with design implications for successfully building models of inter-organizational collaboration aiming for co-production of e-learning courses targeting industry competence needs.

In this paper, we outline the project ProdEx (Expert in Production technology), which is a longitudinal project comprising inter-organizational collaborative competence activities between one university and a manufacturing industry network mainly in the aerospace and automotive sector, starting in 2013 and is still ongoing until 2020 [13]. Throughout the project 
we apply an overall collaborative AR approach [12] including six cases from multi-perspectives actor views; industry managers (two cases), teachers, course design, course practitioners and alumni case. Overall aim is to reach for a sustainable collaborative competence e-learning model (CCeM) that will increase industrial employees' production competences. The question asked is: What are the critical factors facilitating inter-organizational collaborative e-learning design and co-production between university and industry? Given this question, we emphasize critical factors from the results of the various studies that advanced through AR and designoriented actions towards the CCeModel. The process of co-production is analysed through two fields; the industry knowledge needs and the e-learning design of a course program, see Figure 1.

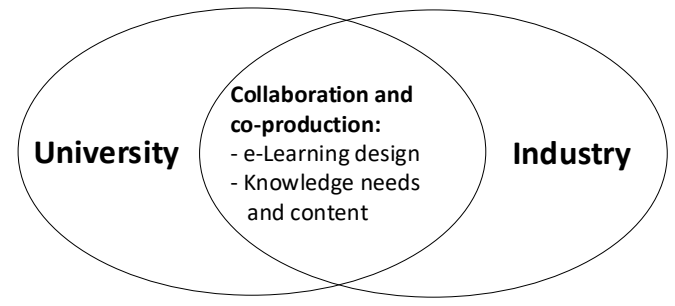

Figure 1. Co-production in inter-organizational collaboration

In the six cases, the overall focus was to capture learning and design activities at the systemic intersection between university and industry (managers and university project group) and between teachers and engineering practitioners. Given all results we in this paper first look back and outline lessons learned from the two ProdEx project phases, initiation and implementation (case 1-5), and then highlight upcoming challenges of the on-going and final dissemination phase (case 6).

In the following, the theoretical framework gives an overview of work-integrated learning, co-construction of knowledge and e-learning design of courses. It ends with theories on learning while boundary crossing. Section 3 outlines the ProdEx project. Section 4, research method, shortly describes how the six cases were approached. Section 5, outlines overall findings from each of the six cases, organized in the phases; initiation, implementation and dissemination. Discussion (section 6), outlines challenges and resolutions of critical factors for successful interorganizational collaborations for a CCeModel. Section 7 , conclusions describes the main contributions.

\section{Theoretical framework}

This section introduces the problems that industries encounter in a transformative digitalized manufacturing and the need for competence development, work-integrated learning and coproduction of knowledge. Thereafter the premises of elearning design challenging the university is outlined. We use boundary crossing as a theoretical lens applied to the overall results of the six studies [14].

\subsection{Work-integrated learning and co- production of knowledge}

Digital transformation today forces the manufacturing industry $[15,16]$ to adapt to Industry 4.0 applications such as artificial intelligence and interconnected machines [17]. Digital transformation further pressure industry practitioners to expand to future skills and the new professions need to facilitate production systems, digital applications and new types of services [18]. These transformative changes of reconfiguring factory plants are pushing the everyday production work and therefore management and practitioners need to constantly to learn and re-learn knowledge that is not even there yet [19].

Hence, the digital industrial transformations [20], affect shop floor practitioners with traditionally low level of formal academic education. Even if they have both deep and long work-based experiences and knowledge $[21,22]$, they need to be strengthened with new types of knowledge and learning that formal education can offer. In line with this, Tynjälä [23] put forward that education should adopt specific features of workplace learning and development of expertise. Combining experience-based knowledge with scientific knowledge tend to be a key for further progression for practitioners. Industry companies therefore need to actively engage in improving their practitioners' competences through new formalised education that can be integrated in work practice, which here is described as work-integrated learning (WIL) [24]. WIL is here defined as a combination of education and practice that need to be understood from an inter-organizational perspective. It is as an umbrella term for a range of approaches and strategies that integrate theoretical knowledge with the practice work. In formal education such perspective need to be purposefully designed within curriculum towards industry needs $[24,25]$.

A growing body of research are defining the concept of co-production in user and technology centered studies [26]. Jasanoff [26] stresses that coproduction includes wide areas, such as making identities, making institutions, making discourses, and 
making presentations. Meaning that co-production encapsulate activities of mutual interest of learning, design and knowledge sharing between multiple stakeholders. Jacoby and Ochs [27] further highlight the interactional approach to explore how coproduction is facilitated from a process-oriented view. With this follows to seek understanding of how processes of knowledge are constructed, rather than to define their ends. The processes co-production includes both the subjects and tools, and the cultural practice of science and technology in which meaning and learning are delineated among stakeholders [28-30].

\subsection{E-learning design}

Traditional university programs are regularly designed for individual purposes, for fulltime oncampus education, and have long planning horizons for developing curricula, course content, and routines. University courses traditionally are not specifically designed for industry companies, and not adjusted to new target groups needs and flexible on-line forms [31-33]. Strategies and actions for an immediate capacity to meet practitioners specific knowledge needs are often problematical [34]. Hence, universities need to readjust their educational programs and courses from the delivery paradigm, towards education targeting new types of learners. They need to find new ways of approaching, designing and implementing blended e-learning courses supporting both individual purposes and work organizations increased competence requests [35].

In addition, digitizing engineering knowledge and integrating experience-based engineering know how, are pedagogically and technically hard [8, 36-39]. For instance, digitizing engineering knowledge, e.g., laboratory and machine dependent tasks, and broadcasting 3D applications [40]. E-learning technologies, applications, digital learning material, web-conferencing systems, video etc. offer a complexity and the new digital framework do not lend itself to qualitative learning [41].

The technology provides us with more and more options, however making them work in dispersed environments and integrated in work contexts, may cause difficulties in and between learners and teachers $[31,32,36,42]$. There is a complexity of designing elearning materials, examinations, instructions, digitalization of lectures for the university staff. Teachers technological knowledge is a key factor for aligning their pedagogical ideas as an integrated part in a digitized course and through various digital communication tools, and applied to company needs [42].

\subsection{Learning while crossing boundaries}

Boundary crossing can be used as a theoretical lens to understand learning that align with professional practices outside the university and to implement workplace experiences and expertise as a mutual design process of engineering e-learning education [14]. Akkerman and Bakker [14] draw the attention to boundaries with the potential of learning at the boundary and by crossing boundaries as dialogical phenomena that reveal certain mechanisms of learning that can develop various sociocultural differences, i.e., discontinuities as functions for identity and practices. They outline four dialogical learning mechanisms that may appear through boundary crossing; identification, coordination, reflection and transformation. Identification concerns how the individual experiences differences of diverse practices. Coordination handles collaborative and routinized exchanges. Reflection expands one's perspective on the practices. Transformation is about collaboration and handles codevelopment for new practices. Boundary crossing can be movements between institutionalized practices such as school and work. As such, boundary crossing can cause discontinuities in interactions between actors, and thereby serve as potential for learning. We argue that boundaries are crossed between the engineering higher education and the industry contexts. Hence, to contribute to our understanding of teachers and practitioners identities in complex learning situations, boundaries and boundary crossing may apply a dialogical viewpoint that conceptualize movements of practitioners and teachers identity and coordination activities of technology, pedagogy and learning [43].

\section{The ProdEx project}

The ProdEx project (Expert in Production technology) was initiated in spring 2013 and continues until end of 2020. The overall aim of the interorganizational collaborative project between university and industry, is to design competence activities in coproduction.

A network of 40 different industry companies within the automotive and aerospace sector are collaborating with one Swedish university. Joint activities are; competence mapping of engineering knowledge needs and content, e-learning design technologies and forms towards developing professional skills for a future digitalized industrial work practice. The project is situated at a Production Technology Centre (PTC), which is affiliated to the university. Research at PTC is focusing on engineering areas such as robotics and automation, cutting processes, sheet metal forming, welding, and additive 
manufacturing. Within these subject areas a total number of 30 various short five-week flexible elearning courses consisting of 2.5 ECTS (European Credits) are designed within the ProdEx project. At the end of the project in 2020, 82 instances of the courses will be completed.

During the initialization of the project in spring 2013, a project organization was organically developed and run by an internal project group at the university. This university project group consists of action researchers (the authors and other university researchers), teachers, information and communication pedagogues, IT technicians, administrators and a program manager. They meet continuously and work in co-production with mapping knowledge needs and design of curricula, e-learning of design (pedagogy and technology, course planning and follow up. This group specifically support individual teachers of the course program. The company network group comprises actors from the manufacturing industry with members such as CEO's, production managers, human resource managers, technicians, etc. with various knowledge and experiences of engineering work practices. They meet around future competence needs and requirements, flexible e-learning design and workintegrated pedagogy. These two groups interrelate in joint activities, e.g. network seminars, co-production of course content with key experts and course evaluation.

\section{Research method}

The overall methodology used for the overall project is a collaborative practice research approach to organize and conduct research of e-learning activities based on close relationship between teachers and practitioners [12]. The approach is a pluralist research methodology that allows for combining action research (AR) with conventional qualitative and design-related studies which emphasize research activities that advances science while at the same time inform professional practice [44]. Such approach facilitates the production of both theoretical and practical knowledge by emphasizing research activities that advances science while at the same time inform professional practice $[10,12]$. A collaborative practice research method acknowledge activities and interventions in close relationship to the on-going practice embracing practice research with focus on understanding the practice, design research with focus on designing artifacts, e.g. e-learning courses and technologies, and action research focuses on changing work practice [44]. Hence, the choice on method approach was based on the nature of the project; longitudinal, different systemic levels, multiple actors, study of changes over time, exploring, designing, evaluating and making interventions and suggesting change efforts.

During the whole research process, the perspective of actions research, encompass the overall research project level $[12,44]$ combined with five case studies and one ADR study [10]. Data collection throughout the project process is a combination of 1) informal data collection through participation in the project group and the company network group, and 2) formal data collection from the six cases, see Figure 2.

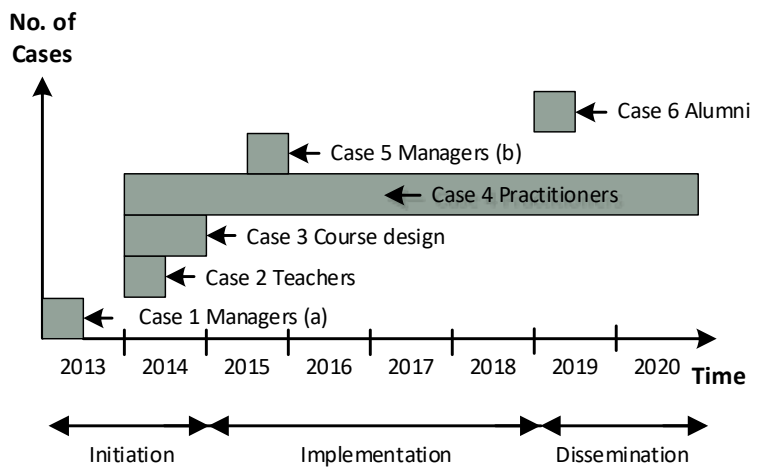

Figure 2. Cases in phases with timeline

The informal data collection was conducted through participations in meetings such as discussions, making suggestions, intervening in forthcoming decisions, giving feedback to the project group/company group etc. Notes were taken and/or audio recorded.

The formal data was collected by qualitative interviews (managers and teachers), and focus group sessions and questionnaire (course participants). Additional data collection was to study design and learning content, video material, LMS instructions, course plans, observing web-conferencing during ongoing courses in cycles over time (part of the ADR case). For both interviews and focus group sessions, a semi-structured thematic interview guide was used. All sessions were audio recorded and participants were taking part in informed consent. Each interview and focus group session lasted from one hour - one hour and a half, and were recorded and verbatim transcribed. The researchers (the authors of this paper, among others) were aware of the power dynamics between interviewees and researchers [45]. Especially when asking sensitive questions about the companies (i.e., product knowledge and/or managerial structures), or the respondents experiences of sensitive information (i.e., course experiences of ICT problems).

The data analysis of all interviews (case 1, 2, 5) and focus groups (Case 4) was ongoing over four years and conducted in iterations. General analysis method used 
was qualitative content analysis to interpret the text data from the transcripts. We used open coding of manifest meanings and categorized the data into the unit of analysis, codes, categories and themes [46, 47]. The analysis focused individuals' (managers, teachers and industry practitioners') expressions of their knowledge experiences and the ongoing collective social interaction around the competence activities, elearning design and co-construction of knowledge. For each individual data set various theories was chosen and applied to shed light on the results. Activity theory [19] was applied as an overall theoretical approach to understand how the project emerged in cycles over time [13].

\section{Competence activities and findings}

Here we outline key research findings from each of the six individual cases performed during six years (2013-2019 and forthcoming) with of a total of 547 respondents, see Table 1 . The overall aim of the ProdEx project was to advance towards a sustainable collaborative competence e-learning model, the CCeModel. Built on the extensive data collection we in this article ask; "What are the critical factors facilitating inter-organizational collaborative $e$ learning design and co-production between university and industry?"

Table 1. Overview of phases, studies and objectives

\begin{tabular}{|c|c|c|}
\hline $\begin{array}{l}\text { Project } \\
\text { phases }\end{array}$ & Cases & Objectives \\
\hline \multirow{2}{*}{ 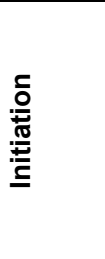 } & $\begin{array}{l}\text { Case 1 } \\
\text { Industry } \\
\text { Managers (a) } \\
\text { Interviews }\end{array}$ & $\begin{array}{l}\text { Manufacturing industry e- } \\
\text { learning readiness and learning } \\
\text { conditions. } \\
\text { Time frame: } 2013 \\
\text { No. of respondents: } 27\end{array}$ \\
\hline & $\begin{array}{l}\text { Case } 2 \\
\text { Teachers } \\
\text { Interviews }\end{array}$ & $\begin{array}{l}\text { Design plans for e-learning. } \\
\text { Time frame: } 2014 \\
\text { No. of respondents: } 5\end{array}$ \\
\hline \multirow{3}{*}{ 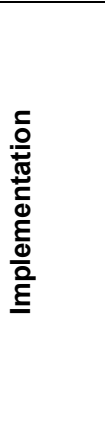 } & $\begin{array}{l}\text { Case } 3 \\
\text { Course design } \\
\text { ADR }\end{array}$ & $\begin{array}{l}\text { Action Design Research in } \\
\text { iterations of three courses. } \\
\text { Time frame: } 2014-2015 \\
\text { No. of respondents: } 36\end{array}$ \\
\hline & $\begin{array}{l}\text { Case } 4 \\
\text { Practitioners } \\
\text { Focus groups }\end{array}$ & $\begin{array}{l}\text { Practitioners' co-production and } \\
\text { learning from courses. } \\
\text { Time frame: } 2014 \text { - } 2019 \\
\text { No. of respondents: } 367\end{array}$ \\
\hline & $\begin{array}{l}\text { Case } 5 \\
\text { Industry } \\
\text { Managers (b) } \\
\text { Interviews }\end{array}$ & $\begin{array}{l}\text { Managers' co-production } \\
\text { towards transformations in the } \\
\text { workplace. } \\
\text { Time frame: } 2015 \\
\text { No. of respondents: } 35\end{array}$ \\
\hline 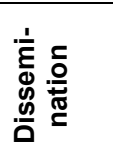 & $\begin{array}{l}\text { Case } 6 \\
\text { Alumni } \\
\text { Questionnaire }\end{array}$ & $\begin{array}{l}\text { Course effects and } \\
\text { transformation in the workplace. } \\
\text { Time frame: } 2019-2020 \\
\text { No. of respondents: } 77 \\
\text { Response rate: } 12 \%\end{array}$ \\
\hline
\end{tabular}

\section{Initiation phase}

Case 1 - Managers. This initial phase departure from the manufacturing companies' knowledge needs and the university ability to meet such competence needs. The inter-organizational process concerned defining companies' specific knowledge needs and the university ability to meet such needs, a process of competence mapping. Competence activities were regular company meetings and the interview case 1, with Human Resource and Production manager in 15 manufacturing companies (27 respondents). Case 1 aimed at defining e-learning readiness for competence initiatives in collaboration with the university. Findings among the companies showed a broad variation of practices and routines for defining expert competences, long-term competence strategies, and external organizational networking with research institutes and higher education. The case resulted in four new constructs; awareness, e-learning maturity, dynamic capability, and co-creativeness. Only two global companies had strategies for strategic collaboration outside their own company. High e-learning readiness and absorptive capacity are two concepts that comprise the capabilities that organizations' need in order to capitalize on e-learning initiatives [48].

Case 2 - Teachers. In spring 2014, the second year of the project, the course plans had been postponed, and no courses were yet designed or implemented. During this rather stressful time, it was decided to perform a teacher study, case 2, which explored teachers' design plans of e-learning courses before actual course implementation. Findings show that teachers' identities and perceptions of e-learning design were related to their pedagogical experiences and technical knowledge. They found it challenging to make strategies and plans for meeting the practitioners' expectations of both practical and theoretical knowledge related to their work practice, i.e., finding pedagogical concepts, technical cases and learning material to include practitioners' experiences and engineering expertise. Digitizing engineering learning content such as labs, programming, drilling and milling cases that align with workplace needs were hard. Overall findings showed that teachers need to cross boundaries between university and industry [14] to have insight in both practices when designing concepts that connect workplace experiences with theoretical learning content, i.e., through work-integrated case methodology [43].

\section{Implementation phase}

Case 3 - Course design. Action design research (ADR) was specifically used for designing the courses and summarized lessons learned from the learning activities in the three initial courses together with 
learning from the company meetings during 20142015. The case included activities applied to the four stages of the ADR method [10]; 1) problem formulation; 2) building, intervention and evaluation BIE; 3) reflection and learning, and 4) formalization of learning. Stage 1 included both competence mapping activities from both case 1 as and course participants interaction. The BIE stage was specifically helpful to design principles towards a generative course model meaning evaluate the IT artifact into a realized design. Through three iterations general design principle resulted in instantiations of the three courses in the first pilot case in 2014, with variously practical results [49]. A formalized elearning course model was designed consisting of 2.5 European credits, 5-6 weeks with maximum 2-4 lecture days at PTC (including final examination day), and additional web-conferences between the lectures (online seminars, labs presentations etc.). The ADR cycles, with the BIE (stage 2), reflection and learning (stage 3), and formalization (stage 4), were setting the course design agenda for further courses. However, there was a need for continued BIE of repeated courses, due to the teachers' various use of e-learning tools, case methodologies and on-line material [13]. Hence, continuous design work for the e-learning courses is still on-going. Until today in 2019, there are 52 implemented courses and about three-four university-industry co-production meetings per year.

Case 4 - Practitioners. This case includes continuous focus group sessions at the end of each course unit. It became clear that practitioners are interested in co-producing knowledge both through actively engaging during the course but also during the focus group sessions. Many practitioners also follow a range of courses within machining, industrial automation, negotiation skills for businesses, additive manufacturing, industry 4.0 etc. This case explores practitioners' perspectives and knowledge construction in order to delineate forms and content of both elearning design and mutual knowledge co-production, as a type of learning trajectory [50]. It also includes the relations between the practitioners and the teachers. The focus group sessions are part of the last design phase of the Building, Intervention and Evaluation (BIE), conducted in case 3 , and as explained above this activity is still on-going. In case 4, data analysis and findings show that practitioners' manifestations of contradictions have different personal motives for competence development than the company objectives. Even if companies are eager to support competence development, they do not consider enough time and daily support for such initiative. Practitioners feel their own motives for learning are key for participating.
Case 5 - Managers (II). This case was a follow-up interview study on manager perspectives, including interviews with six new industry companies. The aim was to recapitulate the industry management's efforts regarding competence work and support for practitioners taking part in the courses and ProdEx. This specific focus concerned how and what actions were taken in the workplace after comprehended competence efforts. We wanted to capture reasons for the various engagement in the project up to now, and why some initial companies only participated in occasional meetings. Findings show that companies' stress that their project participation and collaboration with higher education must be related to their own competence requirement, finding periods for collaboration and time from a stressful production environment. Also, some companies found it hard to encounter an academic environment for the first time through continuous collaboration. Regarding managerial support to practitioners, findings show a broad variety of internal company efforts supporting practitioners' knowledge sharing and work-place transformations. Only two-three companies (both old and new ones) presented a routinized system or support models for follow-ups on practitioners' new learning from the courses. It is further shown that the practitioners themselves are dependent on individual efforts for developing skills needed in a transformative practice. Hence, management strengths for knowledge transfer and knowledge integration in the workplace are low, and individual-dependent. These findings align with the results in Case 4, when practitioners discussed dilemmas of having time and money for working versus studying.

\section{Dissemination phase}

This on-going phase aim to enclose new course implementations and build on a long-term sustainable university organization for inter-organizational collaboration and co-production forthcoming.

Case 6 - Alumni. This case is conducted with a questionnaire aiming to comprehend the effects of competence development by evaluating course effects and eventual transformations in the workplace. Areas included are; finding opportunities to adapt the course program to other subject areas, initiating collaborations with other universities to offer a more extensive course program, extending the company network, and to find smooth internal university administration for the new course program.

Findings show that individuals apply for courses within their knowledge area and their ambition to study is built on their own desire (79\%) or of curiosity to know more about a specific course subject (56\%). Only $15 \%$ of the respondents claim they were 
encouraged to apply by their manager. Of those participating in the courses, $89 \%$ found the course content useful (or very useful) in relation to their own work. Further, $87 \%$ answered that the courses incorporated recent research to a high degree (or a very high).

\section{Discussion: Effects of inter- organizational co-production}

This article has described and summarized findings of a trajectory of three phases, initialization, implementation and dissemination, towards a sustainable model for inter-organizational collaboration between university and industry focusing on e-learning design and co-production of courses and collaboration. The research comprised a six-year longitudinal collaborative action research project including six cases, through a multiple actor perspective; managers, teachers, practitioners, the course unit, and project group $[10,12,51]$.

Overall findings show that increased digitalization creates opportunities, but also challenges and push universities and industries into new forms of collaborations trying to build inclusive co-production, which may create tensions, role-definitions, powerrelations, cultural differences etc. In the initialization phase, companies stressed their low participation to be related to their own competence requirement, mainly because their employees lacked former academic competences. However, the university developed forms for accreditation to join courses enabling a stronger access to courses. During the implementation phase, three design cycles derived into general principles of a course format consisting of five weeks period mixed with web-conferences and two-three physical meetings combined with virtual labs and digital material in the LMS. This phase encountered many challenging activities and e-learning design problems such as finding useful co-production pedagogy within the courses (e.g. case methodologies), mapping relevant and key engineering knowledge through the coproduction meetings between project group and the manager group. The on-going dissemination phase aims at maintaining support for the course program within the university administration and management support of transformation processes in the workplace. Given the research question of critical factors for inter-organizational collaborations, the following challenges and resolutions are defined:

Challenge I: Matching industry competence needs with university knowledge fields

The initial companies' ability and awareness to define expert knowledge and competences varied and earlier collaboration with higher education or research institutes were scarce.

Resolution: The managements' eventual acceptance of the project was a boundary crossing activity [14] happening during the joint company meetings, which engaged the managements' insight into aligning their practitioners to join the courses.

Challenge II: Combining practice-related experiences with theoretical knowledge

A continuing problem was for the university to find enough active engaging companies and management members, and for the companies, to receive ready designed targeting courses from the university in time. Lack of time to define competence needs to make course design plans until implementation stressed the university project group and the teachers.

Resolution: Increased agreements on difference were resolved through continuous negotiations within the focus groups and the co-production meetings.

\section{Challenge III: Defining course forms and cases}

Continuous problems to defining knowledge levels and content when planning for new courses, expanded during the project as more course fields were implemented.

Resolution: To incorporate and strengthening the practitioners as part of the mutual knowledge construction within the courses, three different case design models were developed that variously aimed to activate co-construction of knowledge as situated learning. Even if the learning activities were unstable, and not fully developed and robust, there was a general discussion generating new production technology knowledge through meta-cognitive reflections and insights between the teachers and the practitioners [14].

Challenge IV: Creating course modalities applicable to workplace demands

This challenge concerned the flexibility and blend of the course design described as the course modality (course schedule, number of physical meetings, webconferencing versus physical meetings), forms (elearning technologies and pedagogical strategies), and the trajectory of course design and implementation over the years.

Resolution: Through negotiations between practitioners, teachers and AR researchers, dilemmas and conflicts in the courses and on the management level, were diminished once explicated and transitions into actionable possible solutions were developing.

Challenge VI: Lack of useful tools for knowledge transformations in the workplace learning

An emerging challenge is the lack of management's commitment and follow-up of knowledge transformation of the course participants' newly 
acquired knowledge. It often stays with the individual and is not brought out into the companies.

Resolution: The university has continuously invited managers and course participants to joint coproduction dialogues to support development of best practice and methods for expansive transformations integrated in the workplace.

Challenge V: Establishing a company-network and implementing the courses permanently

The formalization of the joint university-industry collaboration and establishing a solid course format (the blend) included the course modalities, choices of e-learning technologies and pedagogical learning strategies.

Resolution: It does not suffice to only connect people with special expertise and think interaction and knowledge sharing will happen. If mutual coproduction shall occur on many levels, practitioners also need relational expertise for knowledge building. In the future, there must be a continuation between the industry network and the university outside the course program itself.

Challenge VI: Fragmented internal university educational administration processes

University administration is poorly prepared to handle on-going short flexible courses running outside established traditional university programs (i.e. regular BSc and MSc).

Resolution: on-going challenges within the project to resolve (together with university administration and management) are; delays of course advertisement, slow admission process due to validation of real competences, low management prioritization of short courses for competence development and inflexibility of adopting new routines. Not solving the described challenges will affect the long-term company relationships as well as participants' experiences of the course qualities.

Challenge VII: Lack of key teacher competences at the university

The university's capacity to be able to meet specific key competence needs and increased number of applicants for new innovative courses. An example is when the number of applicants to a range of new courses in the subject Industry 4.0, rose to about 140 applicants for solely 20 places. Due to limited teacher resources, this unplanned demand meant that the industry competence needs could not be met as fast as the industry requested.

Resolution: Improved university management prioritization of the ProdEx course program, so that teacher resources are planned and dedicated long-term.

Given the challenges and resolutions described, a summary of critical factors from three perspectives follows:

\section{Industry perspective}

- Real cases support theory-practical intertwining of mutually learning, through co-production.

- Practitioners' aiming for personal continuous competence development on university level creates analytical skills, high-qualitative performances and valuable engagement in the process of co-production

University perspective

- To be problem oriented and curios of e-learning technologies [teachers and practitioners] is a key activity for co-production of e-learning coproduction.

- To have insight into other organizations rules and culture, i.e. abilities for crossing organizational boundaries, is supporting mutual collaboration.

\section{Collaborative perspective}

- The courses create a key joint collaborative adventure, and a respected activity for coproduction of knowledge.

- Stakeholders' abilities to inter-organizational boundary crossing actions creates a key activity for co-production.

- Sustainable and joint industry-university collaborations are important for co-production on long-terms.

We have outlined a trajectory of activities in a collaborative practice between university and industry. To strengthening competences for industrial work, collaborative competence programs between university and industry can have the power of emphasizing individual's engagement and strengthening their learning for new work practices. Thus designing interorganizational e-learning courses is a powerful way of integrating theory and practice as an intertwined coproductive process for knowledge development and formalized in a CCeModel, see Figure 3.

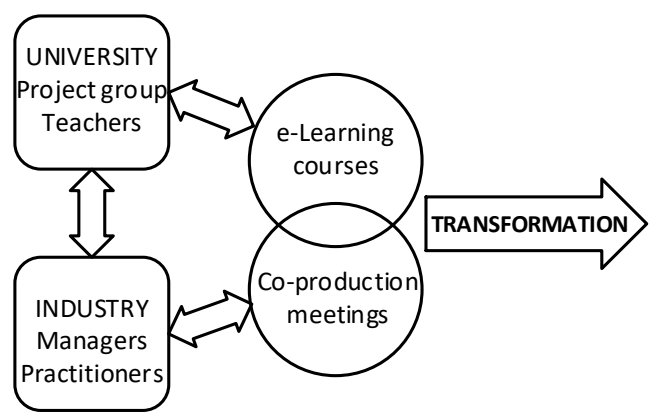

Figure 3. Overview of a Collaborative Competence e-learning Model (CCeModel) 


\section{Conclusions}

This article has outlined a collaborative practice research project that was initiated by two dominant challenges and on-going societal changes. One major challenge is the manufacturing industry emergent need of high-qualified engineers and practitioners due to the increased digitalization, automation and robotization that affect the engineering work practices [18]. As such, new competences, new professional engineering skills and expert knowledge in production technology emerge. The other challenge is the digitalization of elearning courses as a promising affair that challenges the university to open up to external collaboration and new target groups of learners. Such challenges stress the university into readiness of handling new partners and new learning strategies enabling design and coproduction of work-integrated e-learning [50].

While earlier research has discussed the problems of inter-organizational collaboration, our findings show that university and industry are crossing boundaries and become aware of their different organizational work practices when they mutually co-produce knowledge in an e-learning practice [14]. Coproduction creates a social space in and between individuals; contextualizes sharing and giving from two or more perspectives, emphasizing technological artifacts and design, which are creating excitement of new knowledge, learning and positive engagement. Co-production is much more than collaboration, because it prerequisites mutual engagement and trust. Our main contribution suggest that co-production of knowledge entails three levels of activities among actors; to have insight into the purposes and practices of others, the capacity to transform the problems of a practice and together build common knowledge and finally the capacity of mutually co-produce knowledge acted upon in practice towards knowledge transformations in the workplace [13].

\section{References}

[[1] Hardy, C., N. Phillips, and T.B. Lawrence, Resources, knowledge and influence: The organizational effects of interorganizational collaboration. Journal of management studies, 2003. 40(2): p. 321-347.

[2] Argote, L., et al., Knowledge transfer in organizations: Learning from the experience of others. Organizational behavior and human decision processes, 2000. 82(1):p. 1-8.

[3] Ingram, P., Interorganizational Learning. Vol. Chapter 28. 2017: Wiley Online Library.

[4] Majchrzak, A., S.L. Jarvenpaa, and M. Bagherzadeh, $A$ review of interorganizational collaboration dynamics. Journal of Management, 2015. 41(5): p. 1338-1360.
[5] Olson, C.A., J.T. Balmer, and G.C. Mejicano, Factors contributing to successful interorganizational collaboration: The case of CS2day. Journal of Continuing Education in the Health Professions, 2011. 31: p. S3-S12.

[6] Thune, T., Success Factors in Higher Education-Industry Collaboration: A Case Study of Collaboration in the Engineering Field. Tertiary Education and Management, 2011. 17(1): p. 31-50.

[7] Parahakaran, S., Designing and Evaluating Collaborative Projects in Learning Communities: Innovative Practices and Strategies. International Journal of Advanced Corporate Learning, 2016. 9(1).

[8] Lahn, L.C., Dilemmas in the development of e-learning at work. Journal of Workplace Learning, 2004. 16(8): p. 466478.

[9] Lindgren, R., O. Henfridsson, and U. Schultze, Design principles for competence management systems: a synthesis of an action research study. MIS quarterly, 2004. 28(3): p. 435-472.

[10] Sein, M., et al., Action design research. MIS quarterly, 2011. 35(1): p. 37-56.

[11] Nelson, H.G. and E. Stolterman, The design way: Intentional change in an unpredictable world: Foundations and fundamentals of design competence. 2003: Educational Technology.

[12] Mathiassen, L., Collaborative practice research. Information Technology \& People, 2002. 15(4):p. 321-345.

[13] Hattinger, M., Co-constructing Expertise: Competence Development through Work-Integrated e-Learning in joint Industry-University Collaboration. 2018a, University West: Trollhättan.

[14] Akkerman, S.F. and A. Bakker, Boundary crossing and boundary objects. Review of educational research, 2011a. 81(2): p. 132-169.

[15] Ford, M., Rise of the Robots: Technology and the Threat of a Jobless Future. 2015: Basic Books, London, England.

[16] Koren, Y., The global manufacturing revolution: product-process-business integration and reconfigurable systems. Vol. 80. 2010: John Wiley \& Sons, Hoboken, New Jersey.

[17] Lasi, H., et al., Industry 4.0. Business \& Information Systems Engineering, 2014. 6(4): p. 239-242.

[18] Susskind, R. and D. Susskind, The future of the professions: How technology will transform the work of human experts. 2015: Oxford University Press, USA.

[19] Engeström, Y., Learning by expanding: An activitytheoretical approach to developmental research. 2 ed. 2015: Cambridge University Press, United States.

[20] Davies, R., T. Coole, and A. Smith, Review of sociotechnical considerations to ensure successful implementation 
of Industry 4.0. Procedia Manufacturing, 2017. 11: p. 12881295 .

[21] Collin, K. and P. Tynjälä, Integrating theory and practice? Employees' and students' experiences of learning at work. Journal of workplace learning, 2003. 15(7/8): p. 338344.

[22] Wallin, A., P. Nokelainen, and S. Mikkonen, How experienced professionals develop their expertise in workbased higher education: a literature review. Higher Education, 2018: p. 1-20.

[23] Tynjälä, P., Perspectives into learning at the workplace. Educational research review, 2008. 3(2): p. 130-154.

[24] Patrick, C.-j., et al., The WIL (Work Integrated Learning) report: a national scoping study [Final Report]. 2008: Queensland University of Technology.

[25] Trede, F., Role of work-integrated learning in developing professionalism and professional identity. AsiaPacific Journal of Cooperative Education, 2012. 13(3): p. 159-167.

[26] Jasanoff, S., States of knowledge: the co-production of science and the social order. 2004: Routledge.

[27] Jacoby, S. and E. Ochs, Co-construction: An introduction. 1995, Taylor \& Francis.

[28] Rice, M.P., Co-production of business assistance in business incubators: an exploratory study. Journal of business venturing, 2002. 17(2): p. 163-187.

[29] Weinberger, A. and F. Fischer, A framework to analyze argumentative knowledge construction in computersupported collaborative learning. Computers \& education, 2006. 46(1): p. 71-95.

[30] Goldstein, L.S., The relational zone: The role of caring relationships in the co-construction of mind. American Educational Research Journal, 1999. 36(3): p. 647-673.

[31] Govaerts, N. and H. Baert, Learning patterns in organizations: towards a typology of workplace-learning configurations. Human Resource Development International, 2011. 14(5): p. 545-559.

[32] Servage, L., Strategizing for workplace e-learning: some critical considerations. Journal of Workplace Learning, 2005. 17(5/6): p. 304-317.

33] Svensson, L., Challenges for work-integrated e-learning: The case of the Swedish Academy of County Administrations. Journal of Workplace Learning, 2004. 16(8): p. 492-502.

[34] Kirkwood, A. and L. Price, Technology-enhanced learning and teaching in higher education: what is 'enhanced'and how do we know? A critical literature review. Learning, media and technology, 2014. 39(1): p. 6-36.

[35] Porter, W.W., et al., Blended learning in higher education: Institutional adoption and implementation. Computers \& Education, 2014. 75: p. 185-195.
[36] Tynjälä, P. and P. Häkkinen, E-learning at work: theoretical underpinnings and pedagogical challenges. Journal of Workplace Learning, 2005. 17(5/6): p. 318-336.

[37] Billett, S., Workplace pedagogic practices: Coparticipation and learning. British Journal of Educational Studies, 2002. 50(4): p. 457-481.

[38] Thompson, T.L., Digital doings: curating worklearning practices and ecologies. Learning, Media and Technology, 2016. 41(3): p. 480-500.

[39] Dubois, C. and L. Long, Improving the Design of Workplace E-Learning Research. International Journal on ELearning, 2012. 11(4): p. 419-440.

[40] Bourne, J., D. Harris, and F. Mayadas, Online engineering education: Learning anywhere, anytime. Journal of Engineering Education, 2005. 94(1): p. 131-146.

[41] Tavangarian, D., et al., Is e-learning the Solution for Individual Learning. Electronic Journal of e-Learning, 2004. 2(2): p. 273-280.

[42] Kahiigi, E.K., et al., Exploring the e-Learning State of Art. Electronic Journal of e-Learning, 2008. 6(2).

[43] Hattinger, M., Researchers design conceptions of elearning courses targeting industry practitioners' competence needs. International Journal of Continuing Engineering Education and Life-Long Learning, 2018b. 28(3-4): p. 235-253.

[44] Chiasson, M., M. Germonprez, and L. Mathiassen, Pluralist action research: a review of the information systems literature*. Information systems journal, 2008. 19(1): p. 31-54.

[45] Kvale, S., Dominance through interviews and dialogues. Qualitative inquiry, 2006. 12(3): p. 480-500.

[46] Bryman, A., Social research methods. 4th ed. 2012, New York: Oxford university press.

[47] Kohlbacher, F. The use of qualitative content analysis in case study research. in Forum Qualitative Sozialforschung/F orum: Qualitative Social Research. 2006.

[48] Hattinger, M., et al., E-learning Readiness and Absorptive Capacity in the Manufacturing Industry. International Journal of Advanced Corporate Learning (iJAC), 2014. 7(3): p. pp. 33-40.

[49] Hattinger, M. and K. Eriksson. Action Design Research: Design of e-WIL for the Manufacturing Industry. Proceedings of the Americas Conference on Information Systems, AMCIS 2015, Puerto Rico August 13-15, 2015.

[50] Hattinger, M. and K. Eriksson, Co-construction of Knowledge in Work-Integrated E-learning Courses in Joint Industry-University Collaboration. International Journal of Advanced Corporate Learning (iJAC), 2018b. 11(1):p. 10-16.

[51] Mathiassen, L. and P.A. Nielsen, Engaged scholarship in IS research. Scandinavian Journal of Information Systems, 2008. 20(2): p. 1. 